OPEN ACCESS

Edited by:

Ching Hsun Chang,

National Taiwan Normal

University, Taiwan

Reviewed by:

Yuke Tien Fong,

Singapore General

Hospital, Singapore

Catherine Bodeau-Pean,

Independent Researcher,

Paris, France

*Correspondence:

Kun-Shan Wu

kunshan@mail.tku.edu.tw orcid.org/0000-0001-9550-8840

Specialty section:

This article was submitted to Occupational Health and Safety,

a section of the journal

Frontiers in Public Health

Received: 17 February 2021 Accepted: 19 April 2021

Published: 31 May 2021

Citation:

Teng Y-M, Wu K-S and Xu D (2021)

The Association Between Fear of

Coronavirus Disease 2019, Mental Health, and Turnover Intention Among Quarantine Hotel Employees in China.

Front. Public Health 9:668774.

doi: 10.3389/fpubh.2021.668774

\section{The Association Between Fear of Coronavirus Disease 2019, Mental Health, and Turnover Intention Among Quarantine Hotel Employees in China}

\author{
Yi-Man Teng ${ }^{1}$, Kun-Shan $W u^{2 *}$ and Dan $X u^{3}$ \\ ${ }^{1}$ College of Modern Management, Yango University, Fuzhou, China, ${ }^{2}$ Department of Business Administration, Tamkang \\ University, New Taipei, Taiwan, ${ }^{3}$ College of Modern Management, Yango University, Fuzhou, China
}

During the coronavirus disease 2019 (COVID-19) pandemic, quarantine hotel employees face a higher risk of infection while they host quarantine guests from overseas. This is the first research to empirically investigate the psychological effects of operating a quarantine hotel on its employees. The empirical results indicate that heightened fear of COVID-19 leads to adverse mental health issues for quarantine hotel employees and confirm that depression, anxiety, and stress have a significant influence on turnover intention. These findings contribute to the extant knowledge base by uncovering the role of mental health in employee turnover intention. Based on the results, implications are presented for practitioners.

Keywords: COVID-19, quarantine hotel, mental health, fear of COVID-19, turnover intention

\section{INTRODUCTION}

The coronavirus disease 2019 (COVID-19) pandemic has had a significant impact on the health and safety of each country's population, as well as ongoing effects to their economies and societies (1). The pandemic paused the majority of hospitality and tourism industry activities, causing a rapid decline in the average occupancy rates of hotel accommodation (2). The catastrophic result of the COVID-19 crisis is that millions of hospitality industry workers are now unemployed (3).

Since the COVID-19 outbreak, the Chinese government has taken measures to prevent the epidemic from further exacerbation (4), while each country has implemented new policies and procedures in an attempt to control the pandemic. Common measures include social distancing, lockdowns, and directives for the general public to remain in their homes $(5,6)$. In addition, governments worldwide have enforced strict safeguard measures and quarantine restrictions on all passengers from overseas arriving in or returning to the country, including a compulsory 14-day quarantine period in a designated hotel. Many governments have expropriated hotels to be used as temporary quarantine accommodation, referred to as the "quarantine hotel $(\mathrm{QH})$." Following the view of Kolkova (7), companies are responding to this need by intensifying accuracy requirements for forecasting market demand. The QH is the hotel industry's resilience strategy in response to a major global crisis.

The world is still managing the COVID-19 pandemic, and while global attention is largely focused on the impact to physical health, its effect on mental health cannot be ignored (8). Health authorities have recognized that COVID-19 can worsen mental 
health conditions (9). A health crisis, such as the pandemic, can lead to psychological changes that can be instigated by fear, anxiety, depression, or insecurity (10). Prior articles show that in China, $24.9 \%$ of college students suffer from anxiety toward COVID-19 (11), and 37.5\% of Chinese international students' post-traumatic stress disorder (PTSD) PCL-C scores measure as moderate or severe (12). In addition, recent evidence reveals that $35 \%$ of China's general population are psychologically distressed (13) and experience considerable stress, anxiety, and depression (14), with similar findings evident among the people of Saudi Arabia, Russian-speaking respondents, and Israeli University students $(15,16)$. Some tourism literatures also evidence a psychological impact on tourists and the hotel industry throughout the COVID-19 pandemic (17-19). Thus, there is an urgent need to understand the effects of the COVID19 pandemic on mental health, as the current crisis could cause panic (20).

Fear has been one of the primary emotional responses throughout the pandemic $(21,22)$. As understanding of COVID19's biology remains limited, fear regarding the uncertainty of its transmission has increased (15). Prior studies evidence that throughout a pandemic, people tend to experience fear of infection, which results in stress, depression, and anxiety (23), and that uninfected people have a fear of contact with confirmed COVID-19 patients. This is an irrational response that may result from increased fear of COVID-19 $(5,24)$.

Panic and fear can create further issues for positively diagnosed COVID-19 patients and their families as they may feel socially excluded. This can increase their risk of developing psychological problems such as depression and adjustment disorders $(8,10)$. Other fears may stem from concerns regarding work-related changes and retaining employment. Recent research also reveals that COVID-19 influences mental health outcomes such as anger, anxiety, boredom, depression, fear, stigma, stress, and PTSD (6, 25-30). Globalization and increased access to information have made it easy for concerns related to uncertainty to negatively shift toward fear and anxiety, causing more psychological distress among the general public $(24,31)$.

Currently, in China, the COVID-19 pandemic is wellcontrolled; however, confirmed cases from overseas continue to increase. During the pandemic, QH employees are exposed to a higher risk of infection while they host quarantine guests from overseas. The role of a $\mathrm{QH}$ worker resembles that of a medical or health-care professional, as they both have direct contact with quarantine guests. As a result, they are more vulnerable to COVID-19's main route of transmission, which is respiratory droplets. The dilemma for $\mathrm{QH}$ employees is how to manage the additional duties of working in a $\mathrm{QH}$, combined with the greater chance of experiencing psychological issues (depression, anxiety, and stress), and the higher risk of infection for themselves and their families and friends as a result of their increased exposure to COVID-19. Also, QH employees may not have paid sick leave, so they could be at risk of losing their job if they need to self-quarantine or care for an infected family member (32).

Worldwide, human resources are paramount when trying to achieve a competitive advantage in business (33), the loss of which can potentially threaten a hotel's existence. QH employees are affected not only physically by the impact of COVID-19 to their daily duties but also psychologically by the increased risk of contracting the virus, creating fear and persistent mental health challenges such as depression, anxiety, and obsessive behavior (34). Working closely with COVID-19 has also increased their perceived risk, psychological strain, and feelings of helplessness, which has led to some $\mathrm{QH}$ employees questioning whether to continue their careers in the hotel industry. Fear, a negative emotion, and the poor mental health of $\mathrm{QH}$ employees as a result of COVID-19 may cause an increase in turnover intention.

Even as this article is being written, the COVID-19 pandemic continues to evolve and spread. As empirical investigation on the mental health response to COVID-19 among QH employees remains scarce, this research intends to explore the association between fear of COVID-19, mental health, and turnover intention of $\mathrm{QH}$ employees in China.

\section{MATERIALS AND METHODS}

\section{Association Between Fear of Coronavirus Disease 2019 and Mental Health}

Fear is an instantaneous feeling that occurs in response to the awareness of a threat $(26,35)$ and is one of the major underlying factors that can lead to physical and mental health issues (36). A prior study evidenced that there is a profound psychosocial impact on people at an individual level during outbreaks of infection, where they are more likely to experience a fear of falling sick or dying (23). Assessing fear during the ongoing COVID-19 pandemic is essential, and understanding its impact on mental health is critical (20).

Literature from Saudi Arabia and Turkey discuss the association between fear of COVID-19 and mental health in the general population and health-care workers during an epidemic. They state that fear of COVID-19 is a significant contributor to mental health problems, such as intolerance of uncertainty, depression, anxiety, and stress (37-40). Furthermore, Bakioglu et al. (26) indicated a positive association between fear of COVID-19 and depression, anxiety, and stress in the general population of Turkey.

Khattak et al. (22) discussed how fear of the COVID-19 pandemic impacted the mental health of nurses in Pakistan, and they found that it had a significant affect. After adapting the Fear of COVID-19 Scale (FCV-19S) into Turkish, Satici et al. (8) proved that fear of COVID-19 increased mental health issues and decreased life satisfaction. Furthermore, Harper et al. (41) and Taylor et al. (42) demonstrated that fear of COVID-19 had a significant influence on depression and anxiety. Based on these insights, this study's first hypothesis is:

H1. Fear of COVID-19 is positively associated with mental health status, specifically depression, anxiety, and stress.

\section{Association Between Mental Health and Turnover Intention}

Turnover intention is an employee's intention to look for a new job and leave their current place of employment (43). An increase 


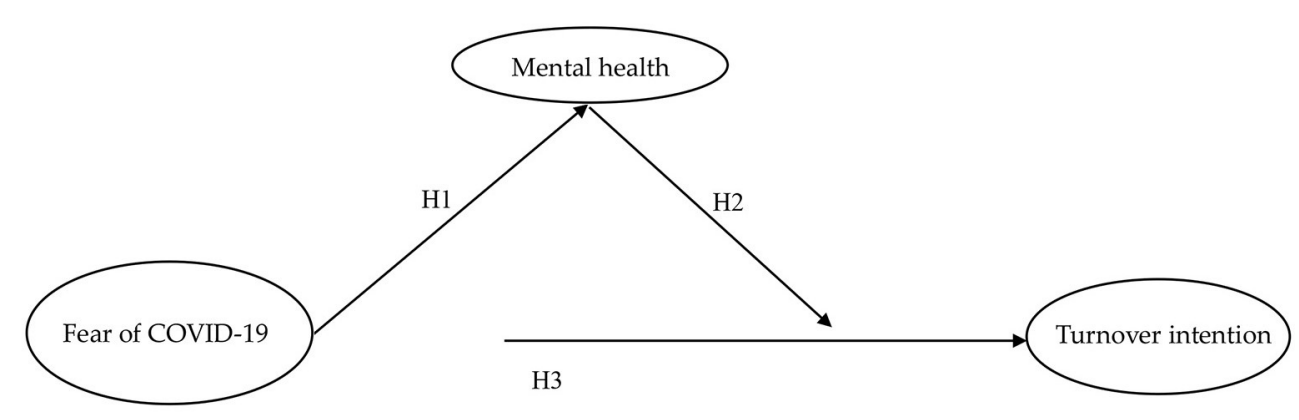

FIGURE 1 | Research conceptual model. Source: own research.

TABLE 1 | Prevalence of DAS in QH employees in China.

\begin{tabular}{llc}
\hline Characteristics & Response & Numbers (\%) \\
\hline Depression symptoms & No $(<14)$ & $96(56.5)$ \\
Anxiety symptoms & Yes $(\geq 14)$ & $74(43.5)$ \\
Stress symptoms & No $(<10)$ & $54(31.8)$ \\
& Yes $(\geq 10)$ & $116(68.2)$ \\
& No $(<19)$ & $156(91.8)$ \\
\hline
\end{tabular}

$D A S$, depression, anxiety, and stress; $Q H$, quarantine hotel.

in staff turnover intention can have serious consequences for an organization (44), as employees are a crucial asset in gaining a competitive advantage (45).

The negative effects of voluntary turnover intention are often discussed in the hospitality industry $(44,46)$. Previous literatures state that depressed hotel employees have a greater intention to leave their jobs $(47,48)$. Some researchers also evidence that employees with more stressful roles, such as hotel employees and nurses, will have increased turnover intention $(49,50)$. QH employees have to cope with not only the physical demands of their new roles but also the threat of contracting COVID-19 and its potential psychological effects. Due to the continuous threat of infection, depression, anxiety, and stress levels in QH employees have increased and could potentially cause a rise in turnover intention. Based on the abovementioned literatures, the second hypothesis is:

H2. Mental health, specifically depression, anxiety, and stress, is positively related to turnover intention.

\section{Association Between Fear of Coronavirus Disease 2019 and Turnover Intention}

Previous studies on nurses found that their fear of COVID-19 and the increased risk of infection strengthened their intentions to leave nursing and seek alternative employment (51). Thus, nurses with higher levels of fear and anxiety also have increased turnover intention (52). A study on Pakistani nurses revealed that their perceived threat of COVID-19 leads to higher levels of anxiety and turnover intention (53). Moreover, De los Santos and Labrague (21) also showed that heightened fear of COVID19 enhanced mental health issues and, consequently, turnover intention, and decreased nurses' job satisfaction. A recent survey suggested that the COVID-19 crisis has instigated fear and an increase in mental health challenges among hospitality workers (34). According to the abovementioned literatures, the third hypothesis is:

H3. Fear of COVID-19 is positively associated with turnover intention.

With reference to the previous literatures, the conceptual model proposed in this study is presented in Figure $\mathbf{1}$.

\section{Questionnaire Design and Measurement Scales}

The questionnaire consisted of two sections. The first section outlined the demographic variables, including gender, age, education, and monthly income. The second section included three scales for fear of COVID-19, mental health effects (depression, anxiety, and stress) caused by COVID-19 and COVID-19-related turnover intention.

The seven-item scale created by Ahorsu et al. (24) measured fear of the COVID-19 pandemic. Each item was scored using a self-rated Likert scale from 1 to 5 . The Chinese version of the Depression Anxiety Stress scale (DASS-21) based on Dong et al. (54) was adapted to measure the mental health status of $\mathrm{QH}$ employees in China. The DASS-21 evaluates the mental health of respondents using the three subscales of depression, anxiety, and stress, each containing seven items (55). All items were scored using a 4-point Likert scale ranging from 0 (didn't apply to me at all) to 3 (much or mostly applied to me). Three items based on Vigoda (56) were adapted to assess the impact of COVID-19 on the turnover intention of QH employees. The 5-point Likert scale was employed to rate the responses, which ranged from 1 (strongly disagree) to 5 (strongly agree).

\section{Data Collection and Procedure}

The data were collected using the convenience sampling method from QHs in Xiamen, Fujian Province, China. There are approximately $50 \mathrm{QHs}$ in Xiamen, as it is the only city in the Fujian Province with airports receiving international flights. Participants were recruited from May 20 to June 10, 2020. The human resource managers from the selected QHs used 
TABLE 2 | Correlations between key study variables.

\begin{tabular}{|c|c|c|c|c|c|c|c|c|c|c|c|}
\hline \multicolumn{2}{|c|}{ Characteristic } & \multirow{2}{*}{$\begin{array}{c}\begin{array}{c}\text { Fear score } \\
\text { (mean } \pm \text { SD) }\end{array} \\
22.55 \pm 7.77\end{array}$} & \multirow{2}{*}{$\begin{array}{c}\mathbf{t} / \mathbf{F} \\
0.022\end{array}$} & \multirow{2}{*}{$\begin{array}{c}\begin{array}{c}\text { Depression } \\
\text { score } \\
\text { (mean } \pm \text { SD) }\end{array} \\
5.52 \pm 4.22\end{array}$} & \multirow{2}{*}{$\begin{array}{c}\mathbf{t} / \mathbf{F} \\
1.248 \\
\end{array}$} & \multirow{2}{*}{$\begin{array}{c}\begin{array}{c}\text { Anxiety } \\
\text { score } \\
\text { (mean } \pm \text { SD) }\end{array} \\
5.90 \pm 4.30\end{array}$} & \multirow{2}{*}{\begin{tabular}{|c|}
$\mathbf{t} / \mathbf{F}$ \\
1.515 \\
\end{tabular}} & \multirow{2}{*}{$\begin{array}{c}\text { Stress score } \\
\text { (mean } \pm \text { SD) }\end{array}$} & \multirow{2}{*}{$\begin{array}{c}\mathbf{t} / \mathbf{F} \\
1.222 \\
\end{array}$} & \multirow{2}{*}{$\begin{array}{c}\begin{array}{c}\text { Turnover } \\
\text { intention } \\
\text { score } \\
\text { (mean } \pm \text { SD) }\end{array} \\
6.11 \pm 2.93\end{array}$} & \multirow{2}{*}{\begin{tabular}{|c|}
$\mathbf{t} / \mathbf{F}$ \\
0.609
\end{tabular}} \\
\hline Gender & Male & & & & & & & & & & \\
\hline & Female & $22.53 \pm 6.41$ & & $4.84 \pm 2.92$ & & $5.05 \pm 3.02$ & & $5.57 \pm 3.15$ & & $5.87 \pm 2.30$ & \\
\hline \multirow[t]{3}{*}{ Age } & Gen Z & $21.47 \pm 8.21$ & 0.485 & $5.12 \pm 4.35$ & 0.418 & $5.28 \pm 4.18$ & 1.695 & $5.66 \pm 4.37$ & 1.298 & $6.72 \pm 3.10$ & 1.942 \\
\hline & Millennials & $22.68 \pm 7.25$ & & $4.92 \pm 3.71$ & & $5.03 \pm 3.83$ & & $5.54 \pm 4.06$ & & $5.91 \pm 2.69$ & \\
\hline & Gen X & $22.95 \pm 5.55$ & & $5.50 \pm 2.42$ & & $6.21 \pm 2.64$ & & $6.60 \pm 2.58$ & & $5.58 \pm 1.80$ & \\
\hline \multirow[t]{4}{*}{ Education level } & $\begin{array}{l}\text { Middle school and } \\
\text { below }^{\mathrm{a}}\end{array}$ & $24.80 \pm 8.40$ & $2.573^{\#}(d<a, b)$ & $5.25 \pm 2.94$ & $3.463^{\star}(b>c, d)$ & $6.60 \pm 3.59$ & $6.183^{\star \star}(b>c, d)$ & $6.55 \pm 3.78$ & $4.694^{\star \star}(b>c, d)$ & $5.65 \pm 2.89$ & 1.393 \\
\hline & $\begin{array}{l}\text { Senior high } \\
\text { school/vocational } \\
\text { school }^{b}\end{array}$ & $23.74 \pm 6.49$ & & $6.45 \pm 3.49$ & & $6.91 \pm 3.46$ & & $7.38 \pm 3.50$ & & $6.36 \pm 2.15$ & \\
\hline & Junior college ${ }^{c}$ & $22.40 \pm 6.28$ & & $4.54 \pm 3.73$ & & $4.54 \pm 3.71$ & & $5.09 \pm 3.89$ & & $5.49 \pm 2.61$ & \\
\hline & $\begin{array}{l}\text { Undergraduate } \\
\text { and above }\end{array}$ & $20.48 \pm 7.31$ & & $4.43 \pm 3.24$ & & $4.41 \pm 3.10$ & & $4.98 \pm 3.45$ & & $6.30 \pm 2.74$ & \\
\hline \multirow{3}{*}{$\begin{array}{l}\text { Monthly income } \\
\text { RMB }\end{array}$} & 6,000 and below ${ }^{a}$ & $23.16 \pm 6.87$ & $2.470^{\#}(a>c)$ & $5.42 \pm 3.65$ & $2.823^{\#}(a>b)$ & $5.66 \pm 3.79$ & 1.492 & $6.14 \pm 3.95$ & 1.520 & $6.10 \pm 2.60$ & 1.294 \\
\hline & 6,001 and above $e^{b}$ & $21.28 \pm 6.39$ & & $3.72 \pm 2.85$ & & $4.38 \pm 3.08$ & & $4.83 \pm 3.13$ & & $5.28 \pm 2.17$ & \\
\hline & $\begin{array}{l}\text { I don't want to talk } \\
\text { about }^{c}\end{array}$ & $19.23 \pm 8.58$ & & $5.31 \pm 2.98$ & & $5.23 \pm 2.77$ & & $5.46 \pm 2.96$ & & $6.23 \pm 2.86$ & \\
\hline
\end{tabular}

$t=$ Student's $t$ test, $F=$ analysis of variance (ANOVA) test.

${ }^{\#} p<0.1 ;{ }^{*} p<0.05 ;{ }^{* *} p<0.01$.

Multiple comparisons between each two categories are done by post-hoc analysis (Fisher's least significant difference). 
TABLE 3 | Measures of constructs reliability.

\begin{tabular}{|c|c|c|c|c|c|}
\hline Constructs/items & $\begin{array}{l}\text { Standardized } \\
\text { factor } \\
\text { loading }\end{array}$ & $\boldsymbol{t}$ & CR & AVE & $\begin{array}{c}\text { Cronbach's } \\
\alpha\end{array}$ \\
\hline Fear 1: I am most afraid of COVID-19. & 0.737 & $16.371^{\star \star \star}$ & 0.941 & 0.695 & 0.928 \\
\hline Fear 2: It makes me uncomfortable to think about COVID-19. & 0.840 & $35.447^{\star \star \star}$ & & & \\
\hline $\begin{array}{l}\text { Fear 3: My hands become clammy when I think about } \\
\text { COVID-19. }\end{array}$ & 0.878 & $53.343^{\star \star \star}$ & & & \\
\hline Fear 4: I am afraid of losing my life because of COVID-19. & 0.734 & $16.012^{\star \star \star}$ & & & \\
\hline $\begin{array}{l}\text { Fear 5: When watching news and stories about COVID-19 on } \\
\text { social media, I become nervous or anxious. }\end{array}$ & 0.893 & $49.679^{\star \star \star}$ & & & \\
\hline $\begin{array}{l}\text { Fear 6: I cannot sleep because I worry about getting } \\
\text { COVID-19. }\end{array}$ & 0.866 & $35.991^{\star \star \star}$ & & & \\
\hline $\begin{array}{l}\text { Fear } 7 \text { : My heart races or palpitates when I think about } \\
\text { getting COVID-19. }\end{array}$ & 0.873 & $40.134^{\star \star \star}$ & & & \\
\hline Depression & 0.862 & $41.745^{\star \star \star}$ & 0.886 & 0.722 & 0.806 \\
\hline Anxiety & 0.914 & $72.297^{\star \star \star}$ & & & \\
\hline Stress & 0.767 & $13.484^{\star \star \star}$ & & & \\
\hline $\begin{array}{l}\text { Turnover intention 1: Due to the impact of COVID-19, next } \\
\text { year I will probably look for a new job outside this } \\
\text { organization. }\end{array}$ & 0.920 & $34.424^{\star \star \star}$ & 0.937 & 0.832 & 0.898 \\
\hline $\begin{array}{l}\text { Turnover intention 2: Lately, I have taken more interest in } \\
\text { job-seeking websites due to COVID-19. }\end{array}$ & 0.876 & $16.817^{\star \star \star}$ & & & \\
\hline $\begin{array}{l}\text { Turnover intention 3: Due to the current situation, I often think } \\
\text { about quitting. }\end{array}$ & 0.939 & $73.595^{\star \star \star}$ & & & \\
\hline
\end{tabular}

COVID-19, coronavirus disease 2019; CR, composite reliability; AVE, average variance extracted.

${ }^{\star * *} p<0.001$.

their staff WeChat group (similar to WhatsApp) to post a recruitment advert. This advert invited employees to participate in the study and explained its background, procedures, and purpose. The survey was conducted with the agreement of the $\mathrm{QH}$ employees, and all their personal information was kept confidential and anonymous.

\section{Methods of Analysis}

The partial least-squares (PLS) model was used for data analysis in this study. According to Pavlou and Fygenson (57), PLS places minimum restrictions on measurement scales, sample size, and residual distributions. To assess the research framework, PLS was conducted in two stages. First, it tested the reliability (indicator and internal consistency reliability) and validity (convergent and discriminant validity) of the measurement model. Second, it also evaluated the structural model and tested the hypotheses (58).

\section{RESULTS}

\section{Respondent Demographics}

A total of 170 participants answered the questionnaire, 58.2\% of whom were women. In terms of ages, $28.2 \%$ were Gen X (born 1965-1976), 53\% were millennials (born 1977-1995), and $18.8 \%$ were Gen Z (born 1996+). With regard to education levels, $11.8 \%$ of employees had middle school or below degree, $27.6 \%$ had senior high school/vocational school, $33.5 \%$ had junior college, and the remaining $27.1 \%$ had an undergraduate or above degree. Three quarters $(75.3 \%)$ of the employees indicated that their individual income was lower than $6,000 \mathrm{RMB} / \mathrm{month}$, $17.1 \%$ indicated their individual income was higher than 6,000 $\mathrm{RMB} /$ month, and the remaining $7.6 \%$ did not want to talk about their individual income.

The prevalence of depression, anxiety, and stress (DAS) in QH employees is shown in Table 1. Using a cutoff score of 14 for depression, 10 for anxiety, and 19 for stress, $43.5 \%$ of respondents reported symptoms of depression, $68.2 \%$ symptoms of anxiety, and $8.2 \%$ symptoms of stress. These results demonstrate that among the respondents, depression symptoms, measured as "Yes/No" responses $(\mathrm{Y} / \mathrm{N})$, are 43.5/56.5 = $0.769(\mathrm{~ns})$; anxiety symptoms $\mathrm{Y} / \mathrm{N} 68.2 / 31.8=2.144$ (significant); and stress symptoms $\mathrm{Y} / \mathrm{N} 8.2 / 91.8=0.09$ (ns). The prevalence of anxiety is 2.1 times more in this sample and confirms that most $\mathrm{QH}$ employees in China have severe symptoms of anxiety, the most serious of the three mental health issues (depression, anxiety, and stress). QH employees' anxiety likely results from concerns regarding the risk of infection while completing their duties and/or excessive exposure to negative media coverage of the COVID-19 pandemic.

As indicated in Table 2, the different fear levels of COVID-19 were insignificant between genders. The one-way ANOVA test showed a significantly lower total score on the FCV-19S in undergraduate and above $\mathrm{QH}$ employees than in senior high 
TABLE 4 | Cross-loadings of constructs.

\begin{tabular}{lccc}
\hline Scale items & Fear of COVID-19 & Mental health & Turnover intention \\
\hline Fear 1 & 0.737 & 0.287 & 0.109 \\
Fear 2 & 0.840 & 0.359 & 0.134 \\
Fear 3 & 0.878 & 0.492 & 0.225 \\
Fear 4 & 0.734 & 0.293 & 0.129 \\
Fear 5 & 0.893 & 0.451 & 0.233 \\
Fear 6 & 0.866 & 0.540 & 0.285 \\
Fear 7 & 0.873 & 0.471 & 0.232 \\
Depression & 0.367 & 0.862 & 0.461 \\
Anxiety & 0.516 & 0.914 & 0.475 \\
Stress & 0.423 & 0.767 & 0.324 \\
Turnover intention 1 & 0.231 & 0.467 & 0.920 \\
Turnover intention 2 & 0.183 & 0.355 & 0.876 \\
Turnover intention 3 & 0.248 & 0.518 & 0.939
\end{tabular}

COVID-19, coronavirus disease 2019.

school/vocational school below employees $(F=2.573, p<0.1)$. Additionally, $\mathrm{QH}$ employees with monthly incomes of 6,000 $\mathrm{RMB} /$ month or below had a higher total FCV-19S score than those who did not want to talk about their income $(F=2.47$, $p<0.1)$.

\section{Measurement Model Assessment}

As outlined in Table 3, all indicator loadings range from 0.734 to 0.969 and are $>0.70$, as recommended by Hair et al. (59). All indicators are significant $(p<0.001)$ and confirm the indicator reliability. All Cronbach's alphas range from 0.806 to 0.928 and surpass the recommended threshold of 0.70 $(59,60)$. Furthermore, the composite reliability (CR) ranges from 0.886 to 0.941 and surpasses the suggested value of $0.70(58,60,61)$. Thus, the internal consistency reliability is established.

The values of average variance extracted (AVE) range between 0.695 and 0.832 and surpass the suggested value of 0.50 (58). These results confirm the convergent validity in all items.

Table 4 shows the cross-loadings of all items that ranked highest among the respective factors. Table 5 demonstrates that each construct of AVE is higher than the squared correlation between constructs. This corresponds with Fornell and Larcker's (61) recommendations. According to the findings, the measurement model is equally valid and acceptable and has discriminant validity, which means that analysis of the structural model can be performed.

\section{Structural Model Measurement}

The empirical results of the research model are displayed in Table 6 and Figure 2. With a sample size of 500, the bootstrap resampling method was applied to measure relationships within the theoretical model, produce $t$-values, and standard errors and to evaluate whether the path coefficient is significant.

As the results show in Table 6, it is evident that fear of COVID-19 does not influence turnover intention $(\beta=-0.016$, $t=-0.345, p>0.05)$. The statistical results confirm that fear of COVID-19 positively influences depression, anxiety, and stress $(\beta=0.516, t=11.408, p<0.01)$. At the same time, depression, anxiety, and stress caused by the COVID-19 pandemic significantly positively impacts turnover intention ( $\beta=0.507, t=6.897, p<0.01)$ and explains $24.9 \%$ of its variance. The connection paths among fear of COVID-19, mental health, and turnover intention are shown in Figure 2.

It should be noted that fear of COVID-19 alone does not influence turnover intention; however, depression, anxiety, and stress caused by fear of COVID-19 positively influences turnover intention.

\section{DISCUSSION}

This study investigates the impact of fear of COVID-19 on QH employees' mental health, specifically depression, anxiety, and stress and turnover intention. The main findings are as follows.

First, the mean score for fear of COVID-19 in QH employees in China exceeds the midpoint of 22.54 (SD: 6.99) and, when compared with similar studies, is higher than that of the population sample of Belarus (16.6) (62), Japan (18.71) (63), Russia, and Belarus combined (17.4) (64) and nurses in Pakistan (22.12) (22).

Second, the results reveal that $\mathrm{QH}$ employees report moderate-to-very severe symptoms of depression, anxiety, and stress: $43.4,68.2$, and $8.2 \%$, respectively. The high prevalence of depression and anxiety could be attributed to increased exposure to guests suspected or confirmed to have COVID-19, apprehension over protecting themselves and their families from contracting COVID-19, and the increased workload of operating a QH.

Third, the QH employees in this study scored highly on the FCV-19S, which is associated with increased scores for their mental health status (specifically depression, anxiety, and stress). As there is a lack of studies involving QH employees, no direct comparison can be made. However, this outcome is consistent with previous studies that evidence that increased fear of COVID-19 is closely related to depression, anxiety, and stress $(8,26)$. While fear is believed to help motivate an individual to react effectively to a perceived threat, persistent, and extreme fear can cause adverse psychological responses, for example, depression, anxiety, and stress (65).

Fourth, increased scores in depression, anxiety, and stress are related to an increase in the turnover intention of QH employees. Depression, anxiety, and stress are the main psychological disorders that affect employees working in an organization. There were similar findings in literature on the hospitality sector, where depression caused employees to leave their jobs and seek employment elsewhere (47). Furthermore, another study evidences that intense anxiety and fear potentially negatively affect the health and well-being of nurses and how effectively they perform their duties during the pandemic (31).

Lastly, fear of COVID-19 does not directly influence the turnover intention of $\mathrm{QH}$ employees. This finding does not concur with the propositions of Barnett and Grabowski (52), De los Santos and Labrague (21), Mo et al. (66), and Ranney et al. 
TABLE 5 | Correlations of constructs and AVE values.

\begin{tabular}{llcc}
\hline Construct & Mean \pm SD & Fear of COVID-19 & Mental health \\
\hline Fear of COVID-19 & $22.54 \pm 6.99$ & $\mathbf{0 . 6 9 5}$ & Turnover intention \\
Mental health & $32.79 \pm 21.18$ & $0.274^{\star \star}$ & $\mathbf{0 . 7 2 2}$ \\
Turnover intention & $5.97 \pm 2.57$ & $0.050^{\star \star}$ & $0.295^{\star \star}$ \\
\hline
\end{tabular}

COVID-19, coronavirus disease 2019; AVE, average variance extracted.

Values on the diagonal in bold = AVE values; variables below the diagonal line = squared correlations between each pair of latent constructs.

${ }^{\star *} p<0.01$.

TABLE 6 | Structure model results.

\begin{tabular}{|c|c|c|c|c|c|}
\hline Hypotheses & Path & Path coefficient & Std. error & $t$-value & Results \\
\hline Hypothesis 1 & Fear $\rightarrow$ mental health & 0.516 & 0.045 & $11.408^{\star \star \star}$ & Supported \\
\hline Hypothesis 2 & Mental health $\rightarrow$ turnover intention & 0.507 & 0.074 & $6.897^{\star \star \star}$ & Supported \\
\hline
\end{tabular}

${ }^{* \star *} p<0.001$.

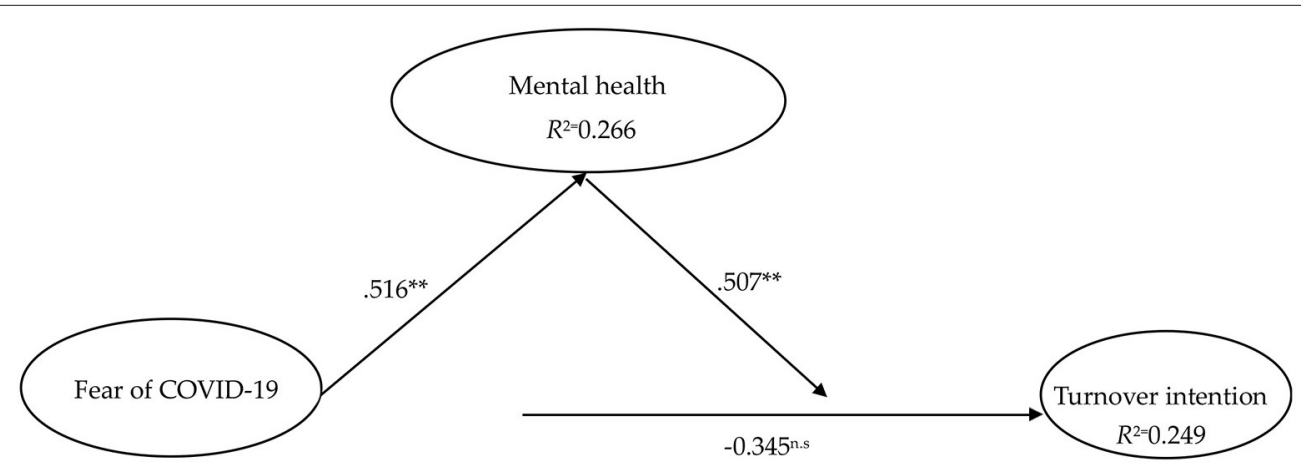

FIGURE 2 | Partial least-squares (PLS) results. Source: own research. ${ }^{* *} p<0.01$; n.s., not significant.

(51), who all state that high levels of fear of COVID-19 increase turnover intention in nurses. This discrepancy may be due to differences in the study participants.

\section{Theoretical Contributions}

The ongoing COVID-19 pandemic has adversely affected the global tourism industry $(19,67)$. This research provides a novel contribution toward understanding the negative effects fear of COVID-19 has on the mental health of QH employees. This study contributes to the psychological research of hospitality industry workers during the COVID-19 crisis in several ways.

First, as far as the authors' knowledge, this article is the first empirical survey investigating the associations among fear of COVID-19, mental health, and turnover intention among $\mathrm{QH}$ employees, thus providing key results in the field of hotel management.

Second, the mental health of $\mathrm{QH}$ employees is a major concern; however, it has rarely been discussed throughout the pandemic. This research applies DASS-21 to investigate the mental health status of $\mathrm{QH}$ employees in China. The empirical results confirm that depression, anxiety, and stress have a significant influence on turnover intention. These findings contribute to the extant knowledge base by uncovering the role of mental health in employee turnover intention. Thus, this research proposes that mental health should be considered an important factor in detecting employee turnover intention.

Finally, this study contributes to the literature on $\mathrm{QH}$ employee turnover intention. Throughout the COVID-19 pandemic, QHs provide accommodation, services, and meals for patients and medical/health-care workers. The $\mathrm{QH}$ also assists guests to comply with government quarantine orders by providing travelers and residents with accommodation for the mandatory 14-day quarantine period. QH employees face higher risks of infection than the general public and are affected not only physically by additional job requirements but also psychologically by the increased threat of contracting COVID-19. Research on QH employees is sparse; thus, it is necessary to investigate the role of $\mathrm{QH}$ employees in the field of hotel management.

\section{Practical Implications}

Resilience and sustainability in the hospitality industry can help businesses recover from a public health crisis by strengthening hotel leadership (68). As excessive fear may exacerbate existing mental health problems and ultimately affect the health and turnover intention of $\mathrm{QH}$ employees, hoteliers should give 
priority to supporting the mental health of their staff during a crisis. Under these circumstances, the following implications are provided for managers of QHs.

First, in order to decrease fear of COVID-19, the $\mathrm{QH}$ managers should implement a well-planned workplace protocol, such as relevant training, response plans, and guidelines and safety practices for caring for quarantine guests. Training is a crucial element to the readiness and competence of $\mathrm{QH}$ employees when faced with disease outbreaks or other forms of disaster. To ensure safe and smooth operation of the adjusted $\mathrm{QH}$, employees must be knowledgeable, skilled, oriented, and proficient in all $\mathrm{QH}$ protocols.

Second, this study's results evidence that QH employees have moderate-to-very severe mental health issues, including symptoms of depression, anxiety, and stress, which will negatively influence turnover intention. Based on this finding, it is suggested that $\mathrm{QH}$ managers build an open communication plan to mitigate uncertainty and decrease the anxiety levels of $\mathrm{QH}$ employees. Open communication pathways provide employees with clear information and updates on the pandemic, the status of quarantine guests, changes to policies and procedures, and impacts to workloads. It also encourages employees to communicate their demands and concerns, which is a significant resource for promoting resilience.

Third, QH managers should cultivate an adequate psychological support program to mitigate and prevent symptoms of declining mental health. For example, periodical online surveys could be used to evaluate and observe the mental health of employees. If any negative psychological symptoms are identified, immediate psychological support, and an appropriate amount of time away from work should be provided. At the same time, hoteliers should develop online mental health education materials and counseling to provide psychological assistance.

Exceptional employee performance is a precious asset for hoteliers. By reducing the mental health issues of employees working in QHs, turnover intention will also decline; and hopefully, after the pandemic is pacified, employees will want to contribute toward the hotel's recovery performance.

Fourth, to reduce the risk of transmitting COVID-19 and cross-contamination, it is suggested that hoteliers implement technological solutions, such as robotic room service to supply meals and a zero-contact check-out. The provision of contactless services is as an effective management tool, as reducing contact with quarantine guests and minimizing their time in public areas will reduce the risk of transmitting COVID-19. The rapid development of non-contact and automated check-in/out

\section{REFERENCES}

1. Nicola M, Alsafi Z, Sohrabi C, Kerwan A, Al-Jabir A, Iosifidis C, et al. The socio-economic implications of the coronavirus and COVID-19 pandemic: a review. Int J Surg. (2020) 75:185-93. doi: 10.1016/j.ijsu.2020.04.018

2. AROMIZE. The State of the Global Hospitality Industry Following COVID19 and What Hoteliers Can Do Now. (2020). Available online at: https:// www.atomize.com/post-covid-19-hospitality-industry (accessed October 30, 2020). processes is essential for the hotel industry both mid- and postpandemic $(69,70)$.

Lastly, hoteliers should also comply with additional benefits strategies, such as reducing workloads or hours, to ensure employee job satisfaction and reduce any psychological impact.

This study is designed to aid hoteliers by highlighting the rectifiable issues and assist the industry's recovery postpandemic. The findings identify the prospective suable issues in order to facilitate the development of human resource management toward supporting employees' psychological health within the hospitality industry.

\section{LIMITATIONS AND FUTURE RESEARCH DIRECTIONS}

As the convenience sampling strategy was used and the only study samples collected were of $\mathrm{QH}$ employees in Xiamen, China, the representativeness of the results is limited. In order to improve the representativeness and generality of sampling, it is necessary to adopt a more systematic and inclusive sampling method. Researchers are also encouraged to explore $\mathrm{QH}$ employees in different countries, and it is recommended that future studies focus on sampling employees in different departments, such as reception, housekeeping, and room service. The use of different data collection methods would also be beneficial. Even though this study used the structural equation model, the research results did not confirm any specific causal relationships between constructs.

\section{DATA AVAILABILITY STATEMENT}

The raw data supporting the conclusions of this article will be made available by the authors, without undue reservation.

\section{ETHICS STATEMENT}

The study protocol was reviewed and approved by the Executive Principal of Yango University, China. An oral consent that follows the principles in the Declaration of Helsinki was obtained from all study participants, and they were instructed to participate or withdraw from the study at any stage voluntarily. Anonymized data were used for analysis and interpretation.

\section{AUTHOR CONTRIBUTIONS}

All authors listed have made a substantial, direct and intellectual contribution to the work, and approved it for publication.

3. Jones P, Comfort D. The COVID-19 crisis and sustainability in the hospitality industry. Int J Contemp Hosp Manag. (2020) 32:3037-50. doi: 10.1108/IJCHM-04-2020-0357

4. Yao Y, Tian Y, Zhou J, Diao X, Di L, Wang S. Impact of population emigration from wuhan and medical support on COVID-19 infection in China. J Epidemiol Glob Health. (2020) (In press). doi: 10.2991/jegh.k.2011 21.001

5. Lin CY. Social reaction toward the 2019 novel coronavirus (COVID-19). Soc Health Behav. (2020) 3:1-2. doi: 10.4103/SHB.SHB_11_20 
6. Pakpour AH, Griffiths MD. The fear of COVID-19 and its role in preventive behaviors. J Concurrent Disord. (2020) 2:58-63. Available online at: https:// concurrentdisorders.ca/2020/04/03/the-fear

7. Kolkova A. The application of forecasting sales of services to increase business competitiveness. J Competitiveness. (2020) 12:90-105. doi: 10.7441/joc.2020.02.06

8. Satici B, Gocet-Tekin E, Deniz ME, Satici SA. Adaptation of the fear of COVID-19 scale: Its association with psychological distress and life satisfaction in Turkey. Int $J$ Ment Health Addiction. (2020) 8:1-9. doi: 10.1007/s11469-020-00294-0

9. World Health Organization. Mental Health and Psychosocial Considerations During the COVID-19 Outbreak. (2020). Available online at: https://apps.who. int/iris/bitstream/handle/10665/331490/WHO-2019-nCoV-MentalHealth2020.1-eng.pdf

10. Zhang J, Wu W, Zhao X, Zhang W. Recommended psychological crisis intervention response to the 2019 novel coronavirus pneumonia outbreak in China: a model of West China Hospital. Precis. Clin Med. (2020) 3:3-8. doi: 10.1093/pcmedi/pbaa006

11. Cao W, Fang Z, Hou G, Han M, Xu X, Dong J, et al. The psychological impact of the COVID-19 epidemic on college students in China. Psychiatry Res. (2020) 287:112934. doi: 10.1016/j.psychres.2020.112934

12. Song B, Zhao Y, Zhu J. COVID-19-related traumatic effects and psychological reactions among international students. J Epidemiol Glob Health. (2020) 11:117-23. doi: 10.2991/jegh.k.201016.001

13. Qiu J, Shen B, Zhao M, Wang Z, Xie B, Xu Y. A nationwide survey of psychological distress among Chinese people in the COVID-19 epidemic: implications and policy recommendations. General Psychiatr. (2020) 33:1-4. doi: 10.1136/gpsych-2020-100213corr1

14. Wang C, Pan R, Wan X, Tan Y, Xu L, McIntyre RS, et al. A longitudinal study on the mental health of general population during the COVID-19 epidemic in China. Brain Behav Immun. (2020) 87:40-8. doi: 10.1016/j.bbi.2020.04.028

15. Al-Hanawi MK, Mwale ML, Alshareef N, Qattan AMN, Angawi K, Almubark $\mathrm{R}$, et al. Psychological distress amongst health workers and the general public during the COVID-19 pandemic in Saudi Arabia. Risk Manag Healthc Policy. (2020) 13:733-42. doi: 10.2147/RMHP.S264037

16. Zolotov Y, Reznik A, Bender S, Isralowitz R. COVID-19 fear, mental health, and substance use among Israeli University students. Int $J$ Ment Health Addiction. (2020) 15:1-7. doi: 10.1007/s11469-020-00351-8

17. Buckley R, Westaway D. Mental health rescue effects of women's outdoor tourism: a role in COVID-19 recovery. Ann Tour Res. (2020) 85:103041. doi: 10.1016/j.annals.2020.103041

18. Hang H, Aroean L, Chen L. Building emotional attachment during COVID19. Ann Tour Res. (2020) 83:103006. doi: 10.1016/j.annals.2020.103006

19. Zhang K, Hou Y, Li G. Threat of infectious disease during an outbreak: In?uence on tourists' emotional responses to disadvantaged price inequality. Ann Tour Res. (2020) 84:102993. doi: 10.1016/j.annals.2020.102993

20. Xiang YT, Yang Y, Wen L, Zhang L, Zhang Q, Cheung T, et al. Timely mental health care for the 2019 novel coronavirus outbreak is urgently needed. Lancet Psychiatr. (2020) 7:228-9. doi: 10.1016/S2215-0366(20)30046-8

21. De los Santos JAA, Labrague L. Impact of COVID-19 on the psychological well-being and turnover intentions of frontline nurses in the community: a cross-sectional study in the Philippines. medRxiv. (2020) (In press). doi: 10.1101/2020.08.05.20167411

22. Khattak SR., Saeed I, Rehman US, Fayaz M. Impact of fear of COVID-19 pandemic on the mental health of nurses in Pakistan. J Loss Trauma. (2020) 1-15. doi: 10.1080/15325024.2020.1814580

23. Hall RCW, Hall RCW, Chapman MJ. The 1995 Kikwit Ebola outbreak: lessons hospitals and physicians can apply to future viral epidemics. Gen Hosp Psychiatry. (2008) 30:446-52. doi: 10.1016/j.genhosppsych.2008.05.003

24. Ahorsu DK, Lin CY, Imani V, Saffari M., Griffiths MD, Pakpour AH. The fear of COVID-19 scale: development and initial validation. Int J Ment Health Addiction. (2020) 1-9. doi: 10.1007/s11469-020-00270-8

25. Ahmed MZ, Ahmed O, Aibao Z, Hanbin S, Siyu L, Ahmad A. Epidemic of COVID-19 in China and associated psychological problems. Asian J Psychiatr. (2020) 51:102092. doi: 10.1016/j.ajp.2020.102092

26. Bakioglu F, Korkmaz O, Ercan H. Fear of COVID-19 and positivity: mediating role of intolerance of uncertainty, depression, anxiety, and stress. Int J Ment Health Addiction. (2020). doi: 10.1007/s11469-020-00331-y
27. Brooks SK, Webster RK, Smith LE, Woodland L, Wessely S, Greenberg N, et al. The psychological impact of quarantine and how to reduce it: rapid review of the evidence. Lancet. (2020) 395:912-20. doi: 10.1016/S0140-6736(20)3 $0460-8$

28. Galea S, Merchant RM, Lurie N. The mental health consequences of COVID19 and physical distancing: the need for prevention and early intervention. JAMA Intern Med. (2020) 180:817-8. doi: 10.1001/jamainternmed.2020.1562

29. Teng YM, Wu KS, Lin KL, Xu D. Mental Health Impact of COVID-19 on Quarantine hotel employees in china. Risk Manag Health Policy. (2020) 13:2743-51. doi: 10.2147/RMHP.S286171

30. Wan W. The Coronavirus Pandemic is Pushing America Into a Mental Health Crisis. (2020). Available online at: https://www.washingtonpost.com/health/ 2020/05/04/mental-health-coronavirus.

31. Bao Y, Sun Y, Meng S, Shi J, Lu L. 2019-nCoV epidemic: address mental health care to empower society. Lancet. (2020) 395:37-8. doi: 10.1016/S0140-6736(20)30309-3

32. Rosemberg MA. Health and safety considerations for hotel cleaners during Covid-19. Occup Med. (2020) 70:382-3. doi: 10.1093/occmed/kqaa053

33. Stanisław B, Krzysztof K, Kamila A. A structure of leadership styles based on the Toyatrity model in the chosen hotel. J Competitiveness. (2015) 7:53-70. doi: 10.7441/joc.2015.01.04

34. Murray K. Hospitality Workers, Job Loss, and COVID-19 Related Addiction. (2020). Available online at: https://www.addictioncenter.com/community/ hospitality-workers-job-loss-and-covid-19-related-addiction/.

35. de Hoog N, Stroebe W, de Wit JB. The processing of fear-arousing communications: How biased processing leads to persuasion. Soc Influ. (2008) 3:84-113. doi: 10.1080/15534510802185836

36. Kumar A, Nayar KR. COVID 19 and its mental health consequences. J Ment Health. (2020) 1-2. doi: 10.1080/09638237.2020.1757052

37. Alyami M, Henning M, Krägeloh CU, Alyami H. Psychometric evaluation of the Arabic version of the Fear of COVID-19 Scale. Int J Ment Health Addict. (2020). doi: 10.1007/s11469-020-00316-x

38. Sulais $\mathrm{E} \mathrm{Al}$, et al. The psychological impact of COVID-19 pandemic on physicians in Saudi Arabia: a cross-sectional study. Saudi J Gastroenterol. (2020) 26:249-55. doi: 10.4103/sjg.SJG_174_20

39. Yildirim M, Arslan G, Alkahtani AM. Do fear of COVID-19 and religious coping predict depression, anxiety, and stress among the Arab population during health crisis? Death Stud. (2021). doi: 10.1080/07481187.2021.1882617

40. Haktanir A, Seki, Dilmaç B. Adaptation and evaluation of Turkish version of the fear of COVID-19 scale. Death Stud. (2020) 1-9. doi: 10.1080/07481187.2020.1773026

41. Harper CA, Satchell LP, Fido D, Latzman RD. Functional fear predicts public health compliance in the COVID-19 pandemic. Int J Ment Health Addict. (2020) 27:1-14. doi: 10.1007/s11469-020-00281-5

42. Taylor S, Landry C, Paluszek M, Fergus TA, Mckay D, Asmundson GJG. Development and initial validation of the COVID stress scales. J Anxiety Disord. (2020) 72:102232. doi: 10.1016/j.janxdis.2020.102232

43. Cheng C, Bartram T, Karimi L, Leggat S. Transformational leadership and social identity as predictors of team climate, perceived quality of care, burnout and turnover intention among nurses. Pers Rev. (2016) 45:1200-16. doi: 10.1108/PR-05-2015-0118

44. Jung HS, Jung YS, Yoon HH. COVID-19: the effects of job insecurity on the job engagement and turnover intent of deluxe hotel employees and the moderating role of generational characteristics. Int J Hosp Manag. (2021) 92:102703. doi: 10.1016/j.ijhm.2020.102703

45. Urbancov H, Linhartov L. Staff turnover as a possible threat to knowledge loss. J Competitiveness. (2011) 3:84-98. Available online at: https://www.cjournal. cz/files/69.pdf

46. Kim SS, Im J, Hwang J. The effects of mentoring on role stress, job attitude, and turnover intention in the hotel industry. Int J Hosp Manag. (2015) 48:68-82. doi: 10.1016/j.ijhm.2015.04.006

47. Boz H, Yilmaz Ö, Arslan A, Koç E. A comparison of depression and turnover intentions of hotel employees in all-inclusive and non-all-inclusive hotels. In: C. Avcikurt, M.S. Dinu, R. Efe, A. Soykan, \& N. Tetik, editors. Global Issues and Trends in Tourism. Sofia: ST. KLI Publisher: St. Kliment Ohridski University Press (2016). p. 372-82.

48. Kilic R, Boz H, Koc E. Depression turnover intention among hotel employees. J Manage Economics Res. (2016) 14:318-31. doi: 10.13140/RG.2.1.3168.0964/1 
49. Kuo HT, Lin KC, Li IC. The mediating e? ects of job satisfaction on turnover intention for long-term care nurses in Taiwan. J Nurs Mana. (2014) 22:225-33. doi: 10.1111 /jonm.12044

50. Wen B, Zhou X, Hu Y, Zhang X. Role Stress and turnover Intention of front line hotel employees: the roles of burnout and service climate. Front Psychol. (2020) 11:36. doi: 10.3389/fpsyg.2020.00036

51. Ranney M.L, Griffeth V, Jha AK. Critical supply shortages-The need for ventilators and personal protective equipment during the COVID-19 pandemic. N Engl J Med. (2020) 382:41. doi: 10.1056/NEJMp2006141

52. Barnett ML, Grabowski DC. Nursing Homes are ground zero for COVID19 pandemic. JAMA Health Forum Mar. (2020). Available online at: https:// jamanetwork.com/ channels/health-forum/fullarticle/2763666

53. Irshad M, Khattak SA, Hassan MM, Majeed M, Bashir S. How perceived threat of Covid-19 causes turnover intention among Pakistani nurses: a moderation and mediation analysis. Int J Ment Health Nurs. (2020) 30:350. doi: 10.1111/inm.12775

54. Dong H, Yang F, Lu X, Hao W. Internet addiction and related psychological factors among children and adolescents in China during the coronavirus disease 2019 (COVID-19) epidemic. Front Psychiatr. (2020) 11:00751. doi: 10.3389/fpsyt.2020.00751

55. Lovibond PF, Lovibond SH. The structure of negative emotional states: comparison of the Depression Anxiety Stress Scales (DASS) with the beck depression and anxiety inventories. Behav Res Ther. (1995) 33:335-43. doi: 10.1016/0005-7967(94)00075-U

56. Vigoda E. Organizational politics, job attitudes, and work outcomes: exploration and implications for the public sector. J Vocat Behav. (2000) 57:326-47. doi: 10.1006/jvbe.1999.1742

57. Pavlou PA, Fygenson M. Understanding and predicting electronic commerce adoption: an extension of the theory of planned behavior. Manag Inf Syst Q. (2006) 30:115-43. doi: 10.2307/25148720

58. Hair J, Hult GT, Ringle C, Sarstedt M. A Primer on Partial Least Squares Structural Equation Modeling (PLS-SEM), 2nd Edn., Thousand Oaks: Sage (2017). doi: 10.15358/9783800653614

59. Hair J, Ringle C, Sarstedt M. PLS-SEM: indeed, a silver bullet. J Market Theor Pract. (2011) 19:139-52. doi: 10.2753/MTP1069-6679190202

60. Anderson JC, Gerbing DW. Structural equation modeling in practice: a review and recommended two-step approach. Psychol Bull. (1988) 103:41123. doi: 10.1037/0033-2909.103.3.411

61. Fornell C, Larcker DF. Evaluating structural equation models with unobservable variables and measurement error. J Mark Res. (1981) 18:39-50. doi: $10.1177 / 002224378101800104$
62. Reznik A, Gritsenko V, Konstantinov V, Khamenka N, Isralowitz, R. COVID19 fear in Eastern Europe: validation of the fear of COVID-19 scale. Int J Ment Health Addict. (2020). doi: 10.1007/s11469-020-00283-3

63. Masuyama A, Shinkawa H, Kubo T. Development and validation of the Japanese version fear of COVID-19 scale among adolescents. PsyArXiv. (2020) doi: 10.31234/osf.io/jkmut

64. Gritsenko V, Skugarevsky O, Konstantinov V, Khamenka N, Marinova T, Reznik R, Isralowitz R. COVID 19 fear, stress, anxiety, and substance use among Russian and Belarusian University students. Int J Ment Health Addict. (2020). doi: 10.1007/s11469-020-00330-z

65. Gorman JM. Fear and Anxiety: The Benefits of Translational Research. Arlington, VA: American Psychiatric Publishing, Inc (2008).

66. Mo Y, Deng L, Zhang L, Lang Q, Liao C, Wang N, et al. Work stress among Chinese nurses to support Wuhan for fighting against the COVID-19 epidemic. J Nurs Manag. (2020) 28:1002-9. doi: 10.1111/jonm. 13014

67. Sharma A, Nicolau JL. An open market valuation of the e?ects of COVID19 on the travel and tourism industry. Ann Tour Res. (2020) 83:102990. doi: 10.1016/j.annals.2020.102990

68. Zhang J, Xie C, Wang J, Morrison AM, Coca-Stefaniak JA. Responding to a major global crisis: the effects of hotel safety leadership on employee safety behavior during COVID-19. Int J Contemp Hosp Manag. (2020) 32:3365-89. doi: 10.1108/IJCHM-04-2020-0335

69. Knight DW, Xiong L, Lan W, Gong J. Impact of COVID-19: research note on tourism and hospitality sectors in the epicenter of Wuhan and Hubei Province, China. Int J Contemp Hosp Manag. (2020) 32:3705-19. doi: 10.1108/IJCHM-04-2020-0278

70. Jiang Y, Wen J. Effects of COVID-19 on hotel marketing and management: a perspective article. Int J Contemp Hosp Manag. (2020) 32:2563-73. doi: 10.1108/IJCHM-03-2020-0237

Conflict of Interest: The authors declare that the research was conducted in the absence of any commercial or financial relationships that could be construed as a potential conflict of interest.

Copyright (c) 2021 Teng, Wu and Xu. This is an open-access article distributed under the terms of the Creative Commons Attribution License (CC BY). The use, distribution or reproduction in other forums is permitted, provided the original author(s) and the copyright owner(s) are credited and that the original publication in this journal is cited, in accordance with accepted academic practice. No use, distribution or reproduction is permitted which does not comply with these terms. 